\title{
Editorial
}

\section{Steps toward greater internationalization}

Japanese science gained a big boost this year with the awarding of the Nobel Prize in chemistry to two prominent scientists, Professor Akira Suzuki of Hokkaido University and Professor Ei-ichi Negishi of Purdue University. Together with Prof. Richard Heck of Delaware University, their independent work on palladium-catalyzed cross coupling has led to the development of a chemical tool that is now widely used in production of new drugs and electronics by facilitating more efficient linking of carbon atoms. As the local media focused on the academic contribution of these two Nobel laureates, we also got a glimpse on their philosophies in life that in a way led to their success in scientific research, and their recognition in Japan, in the international scientific community, and eventually, the awarding of the most coveted honor in science. It is interesting to note that both scientists emphasized the need for young Japanese researchers to broaden their horizons by studying abroad in order to gain new perspectives on many aspects about science. Prof. Negishi who was once an employee of a private company before he moved to the US and started a teaching and research career at Purdue University, emphasized the need for Japanese researchers to go abroad and to see Japan from the outside world. At the same time, Prof. Suzuki also urged senior academics to exert more efforts so that the younger generations will understand the crucial role of science and technology for Japan to continue to compete globally. Now more than ever, the scientific community as well as the policy decision makers must seriously consider these suggestions.

In recent years, the number of Japanese researchers going abroad for graduate or postgraduate studies has been gradually decreasing. This can be attributed to the lack of government support for researchers willing to study abroad, concerns about the difficulty of getting a permanent position after finishing post doctoral studies in foreign countries, or just the lack of interest to study abroad for the reason that Japan has much better research facilities than most foreign countries. Many of members of the Japanese Society of Breeding can attest how their experience of doing research in foreign countries has broadened their outlook and visions for future researches. Conducting research with other experts in the field allows a researcher to access to resources and cutting-edge technology that can facilitate more innovative research activities, therefore providing opportunities to gain more wisdom in tackling a research objective.

The issue on intellectual property rights has also been highlighted in association with this year's Nobel Prize as Prof. Suzuki mentioned that he did not claim patent for his discoveries because he believed that new technologies should be freely used to the wider benefit of the society. This openness allowed private companies to use his technology in a wide range of applications from anticancer drugs and agricultural pesticides to advanced displays and electronic chips in computers. In the case of crop breeding, breeders in general wish that their new crop variety be widely cultivated to satisfy the demands of consumers. Currently, the breeders' intellectual property rights are well protected by related laws, which make it unrealistic to release a new variety without official registration. However, although the variety name of a crop became famous, as in the case of 'Fuji' apple or 'Koshihikari' rice which are now well known even outside Japan, the breeder's name or the institution that bred these varieties is never known at all to consumers. There must be a way to properly recognize or publicize the efforts of breeders so that they will be encouraged to work further utilizing new strategies, and so that consumers could better appreciate the importance of breeding.

We will always depend on various plant resources produced from around the world. As discussed at COP10 held in Nagoya in October 2010, no limitation should be attached on the use of plant genetic resources useful to mankind but the ultimate rights to such resources should be given to the country of origin. Towards this end, breeding objectives must remain an international issue for breeders and researchers. So we have to strive to develop novel varieties that will benefit not only the Japanese society but also the people from other countries who do not have the resources or the technology to develop new varieties that are well adapted to their needs.

Takuji Sasaki

Editor-in-chief

National Institute of Agrobiological Sciences 